\title{
La patrulla multiétnica en la Segunda Guerra Mundial: nuevas perspectivas sobre el cine de combate
}

\author{
Francesc SÁNCHEZ BARBA \\ Departament d'Història i Arqueologia (Secció d'Història Contemporània) \\ Universitat de Barcelona \\ siscusanchez@ub.edu
}

\begin{abstract}
RESUMEN
Se repasa aquí la evolución del cine de la Segunda Guerra Mundial que tiene como centro la peripecia de un pequeño grupo de soldados -patrulla o escuadrón- sometido a la tensión del combate y que presentan orígenes culturales diversos. Así mismo se revisarán aportaciones como las de Quentin Tarantino (Malditos bastardos, 2009) o David Ayer (Corazones de acero, 2014) en las que la violencia y el deseo de venganza son síntomas del desencanto y el pesimismo ante los conflictos bélicos actuales.
\end{abstract}

Palabras clave: cine, combate, patrulla, Segunda Guerra Mundial, soldados.

\section{Multhietnic patrol in World War II. New perspective on cinema combat}

\begin{abstract}
We are going to review the evolution of the cinema in the Second World War focused on the adventures of a small group of soldiers from different cultural origins, belonging to either a patrol or a squadron, suffering from the stress and tension of the fighting.

We are also going to revise some contributions such as those of Quentin Tarantino (Inglourious Basterds, 2009) and David Ayer (Fury, 2014). Violence and the wish for revenge are signs of discontent and pessimism in front of current states of war.
\end{abstract}

Keywords: cinema, combat, patrol, The Second World War, soldiers.

La Segunda Guerra Mundial, la última de las supuestas guerras justas, de acuerdo con la alusión irónica contenida en el título del libro de Jacques R. Pauwels (2002), reúne un inmenso catálogo de traumáticas experiencias que, definitivamente, hicieron saltar por los aires la idea de un progreso tecnológico asociado irremediablemente al fortalecimiento de la paz y de la solidaridad humanas. 
En febrero de 1992 tuvo lugar en Barcelona el Congreso Internacional sobre Guerra, Cine y Sociedad cuya conferencia inaugural (Guerra, Medios Audiovisuales y Sociedad) corrió a cargo de Pierre Sorlin que ya constataba empíricamente que el cine siempre tuvo un gran interés en representar la guerra en las pantallas:

El cine, desde su nacimiento ha ilustrado, ha representado la guerra. Es sabido que uno de los primeros noticiarios fue una reconstitución de la explosión de acorazado Maine en la ensenada de La Habana, que los operadores de los hermanos Lumière filmaron aspectos de la revolución rusa de 1905 y de la guerra con el Japón, que el primer «reportaje» cinematográfico de larga duración fue tomado por cineastas yanquis durante la guerra civil mexicana. (Sorlin 1993: 7)

En mayor medida que la literatura, el cine, especialmente entre los contendientes, se sumó de manera masiva a la llamada de los organismos públicos, pero también de las productoras y de los particulares para sumarse al esfuerzo de guerra. Así, los noticiarios del frente y los documentales de propaganda contribuyeron a dar cuenta de las operaciones militares, pero también se erigieron en poderosas máquinas de propaganda: «películas que moldean la opinión pública e imágenes positivas de películas se traducen en la imagen positiva del Ejército que es una imagen heroica, de camaradería y patriotismo» ${ }^{1}$. Si la Primera Guerra Mundial fue presentada en el cine anterior a 1939 como una cuestión de oficiales caballerosos, de ideales y de héroes individuales, la Segunda Guerra Mundial significó la irrupción de los colectivos multiétnicos cuyos representantes y valores nacían de un mundo cada vez más «globalizado» en el que era más fácil asumir el esencial Why We Fight (Basinger 1986: 87).

En el libro La II Guerra Mundial y el cine (1975-2004) publicado en 2005, intenté explorar qué nuevos caminos y aspectos se podían detectar en la filmografía reciente sobre esa contienda planetaria teniendo en cuenta el proceso de desaparición del bloque socialista europeo, el entonces imparable y pujante espíritu de integración europea que culminó en 2004 con la ampliación de la Unión Europea de 15 a 25 miembros:

La filmografía sobre la II Guerra Mundial en estos últimos 25 años se ha visto fortalecida con la puesta en cuarentena de los códigos censores que constreñían la presentación del horror, aunque no siempre lo más escalofriante desafía las reglamentaciones que preservan al espectador. Acostumbrados en los años setenta a la presencia, a veces no requerida, de la sangre, los testimonios de los verdugos, la revelación de atrocidades ha llegado al gran público de una forma mucho más patente. De todo ello surgen debates interesantes entre lo que ha de ser mostrado y el cómo ha de ser mostrado o lo que es lo mismo, sobre la necesidad de crear códigos de autorregulación en la presentación de la violencia, tenga o no una base real.

Más allá del personaje-tipo del villano nazi, invitado de lujo en la saga de Indiana Jones, que se muestra resistente al paso del tiempo (con delirios esotéricos, perver-

${ }^{1}$ Opinión de Philip Strub, responsable de las relaciones entre los estudios y el Pentágono, que son emitidas en una entrevista que aparece en la producción francesa Hollywood y el Pentágono en un episodio de la serie televisiva La Noche Temática emitido en diciembre de 2004. 
siones a la carta, conocedor de torturas, megalomanía...), el cine alrededor de la II Guerra Mundial ha exhibido una capacidad de regeneración importante sin desdeñar los modos de representación anterior (films de combate, romances en contextos inciertos...) introduciendo gran parte de los olvidados (mujeres campesinas, héroes de la resistencia judía, gitanos, norteamericanos de origen japonés, colaboradores del régimen nazi, miembros de los sonderkommando...). Algunas filmografías (la alemana, la suiza, la francesa...) desde el cine de ficción o de no ficción, han proyectado la luz sobre zonas oscuras de su propio pasado -aunque se hagan extensivas a la mayoría de gobiernos-, revisando cuestiones tan espinosas como el silencio ante las atrocidades nazis o la instauración de trabas legales para acoger refugiados. (Sánchez Barba 2005: 123-124)

Reediciones de autores clásicos o nuevos estudios han puesto de manifiesto errores importantes y nuevos interrogantes como el suscitado por el pobre papel de las tropas francesas que el historiador y combatiente March Bloch (en el Ejército y ya en 1943 en la clandestinidad con el movimiento Franc-Tireur) en las dos grandes guerras mundiales denuncia en su magnífica crónica La extraña derrota (Bloch, 2002). Redactada entre julio y septiembre de 1940 se describe la calamitosa coordinación entre los Estados mayores de Gran Bretaña y Francia y la velocidad en la ejecución de las operaciones de los nazis. Antony Beevor (2002) por su parte recuerda la capacidad de algunas unidades multinacionales de las Wafen-SS (que bien podían ser las que aparecen referenciadas en el film Fury) que aglutinaban a fanáticos de los países conquistados que se aprestaron a una defensa más que notable de los territorios aún en manos del Tercer Reich en la primavera de 1945 pese a mantener una relación encendida con la Wehrmacht. Pueden mencionarse unidades como la división Norland que incorporaba sobre todo a daneses y noruegos, pero también a suecos, finlandeses o estonios, la división Nederland con elementos de los Países Bajos o la división Carlomagno con 1000 franceses que es descrita como «grupo mal avenido de intelectuales de derecha, trabajadores y aristócratas reaccionarios a los que no unía otra cosa que una feroz convicción anticomunista» (Beevor 2002: 134).

De la revisión de catálogos y libros especializados se desprende que, en el caso de la industria estadounidense, el número de filmes de ficción conectados de una u otra manera con la coyuntura bélica alcanzó su apogeo entre 1943 y 1946 mientras que, en el caso de la Unión Soviética, la posguerra bajo el dominio de Stalin (19451953) sería el período más prolífico. Grandes producciones como Veliki perelom (1946) de Fridrikh Ermler, ficción sobre el asedio de Stalingrado; La caída de Berlín (Padenie Berlina, 1949) de Mikhail Tchiaurelli, combinando la espectacularidad del avance de tanques y aviones hacia la capital nazi, con el consabido agradecimiento de las masas al Stalin salvador o la simbiosis de documental y dramatización en La batalla de Stalingrado (Stalingradskaya bitva, 1950) de Vladimir Petrov, donde aparecen caracterizados algunos de los líderes políticos y militares de la guerra, serían algunos ejemplos del período ${ }^{2}$.

${ }^{2}$ Cfr. Butler (1974); Whiteclay, Chambers II y Culbert (1996); Jeavons (1974; Morella, Epstein y Griggs (1975), entre otras obras especializadas. 
El atractivo de lo bélico para la gran pantalla aumenta con el trasunto de un pequeño cuerpo o unidad del ejército que posibilita una mejor identificación frente a ese intento colosal de reproducir los grandes acontecimientos bélicos (presentados de manera más imparcial desde los años 60). En esos relatos, a menudo se pone el acento en las difíciles decisiones que han de tomar los grandes estadistas y generales. Pero no es en los despachos ni en los estados mayores en los que se fragua la popularidad del género que prefiere el cambio de escala, acercándose sobre el terreno para saber más de la lucha de los que fueron al frente y que, voluntariamente o no, tuvieron el valor para acometer la empresa que cada estado les encomendó. Aunque pueda parecer contradictorio, es en el cultivo del género de lo bélico en el que a veces se desarrolla un discurso pacifista que pone en tela de juicio la irracionalidad de toda carrera armamentística. La acotación genérica de lo bélico es realmente compleja sin echar mano de una especie de acuerdo tácito entre comunidades de espectadores que aceptarían determinados recursos, planteamientos o estilemas que se irían configurando a través del tiempo. Esa especie de contrato entre productores y público se despliega de una manera muy diferente en períodos bélicos o prebélicos y si, pese a las bajas, se suma la victoria:

«Vistos en conjunto, los géneros (neo)clásicos más destacados eran la epopeya, la tragedia y la comedia, mientras que el melodrama, las aventuras y el cine romántico son los más sobresalientes géneros cinematográficos. (...) Si el género fuera una categoría inmutable y transhistórica, entonces podríamos esperar una cohesión entre los usuarios de los géneros, en cambio, descubrimos que los géneros cinematográficos no se desarrollan de la misma manera que sus predecesores». (Altman 2000: 242)

La patrulla, con voluntad decidida de pervivencia en el tiempo ofrece un excelente mosaico de vivencias envueltas en la amenaza constante y, además, en el entrelazado necesario de estrategias y ritmos entremezclados a lo largo de días y semanas. La obligada colaboración y la especialización de sus diversos miembros ayuda a constantes interacciones que posibilitan ciertos estallidos de duda, protesta y resistencia.

En el Cuadro 1 intento hacer visible algunos de los retos más relevantes de ese protagonista colectivo que deambula de una manera destacada en muchos de los filmes de combate ${ }^{3}$.

${ }^{3}$ En los dos casos que principalmente analizaré nos encontramos con un grupo que potencia claramente el impacto de sus acciones (Malditos bastardos) ya que la movilidad y sus métodos casi primitivos contribuyen a la creación del mito mientras que en Corazones de acero estamos frente a una unidad condenada a seguir sujeta a un tanque averiado que, pese al aislamiento y al fracaso parcial, deciden librar una última batalla en la vanguardia en aras de proteger a las tropas de tierra que han quedado atrás deteniendo el avance de un cuerpo de élite. No se trata de Leónidas y sus espartanos, pero el combate librado tiene resonancias igualmente épicas. 
Cuadro 1. Un esquema de análisis de la patrulla (Elaboración propia)

\section{UN ESQUEMA DE ANÁLISIS DE LA PATRULLA}

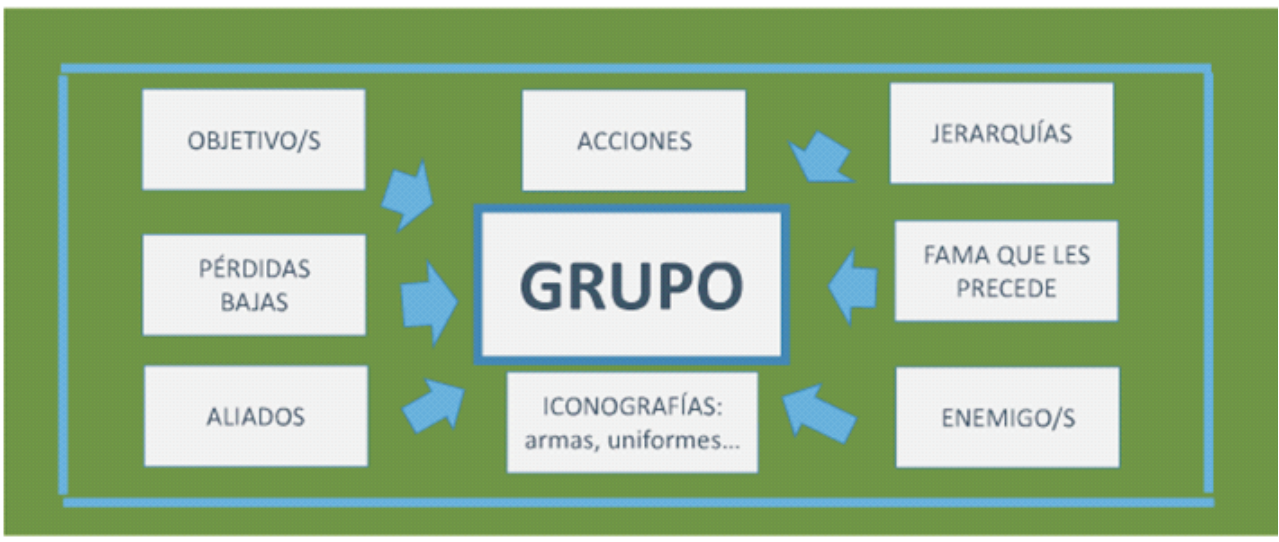

Jeaninne Basinger califica la patrulla multiétnica como aquella compuesta no solo por soldados de diferente rango, procedencia social y formación cultural, sino que se caracteriza por otras marcas como por ejemplo la edad, la veteranía o la unidad militar. Cuando hablamos de unidades especiales conformadas para la realización de determinadas misiones, a menudo se suman militares procedentes de cuerpos y destinos que, frente al carácter homogeneizador de lo militar, deberán mantener una estrecha convivencia pese a que esa proximidad pueda ser asfixiante. La distancia entre la oficialidad y la soldadesca conlleva un cierto misterio en el origen del superior que, tal vez, se desvelará en el clímax de la historia. En el caso del ejército norteamericano, el origen racial, la diferenciación religiosa, el grupo étnico de procedencia, se suma a otras estratificaciones (nivel de estudios, profesionalidad o no del soldado) más habituales. En los ejércitos fascistas, la pertenencia al partido único puede generar el recelo de los militares profesionales más acostumbrados a cierta caballerosidad aparente ${ }^{4}$. Se distinguen otros elementos de análisis: 1) El marco: batalla, acción u operación concreta; 2) Los personajes o actantes; 3) la estructura narrativa y 4) las actitudes y valores culturales individuales, grupales, ins-

${ }^{4}$ La necesidad de acercar los relatos (narraciones visuales y cinemáticas) al público llevaban de manera implícita la inclusión de determinados personajes con los cuales pudiesen establecerse mecanismos de identificación y focalización y es ahí donde entra en juego una unidad suficientemente amplia para que se desarrollen interrelaciones y niveles jerárquicos y de proximidad-distanciamiento pero no demasiado amplio para que nos perdamos en el reconocimiento de esos individuos que, no olvidemos, manifiestan ciertas marcas estandarizadas que despersonalizan su origen (uniforme, obediencia, veteranía...). 
titucionales o estatales (Basinger 1986: 23-25). La ecuación que funcionaría para definir ese específico film de combate que centra este texto se expresaría así:

Film de combate $=$ héroes + mezcla de tipos + objetivos militares a conseguir

En ese microcosmos se mueven a menudo los héroes que han sido estudiados de diferentes formas y que pueblan los imaginarios de todas las civilizaciones y pueblos y asimismo la literatura, las tradiciones orales y mitos y, también el cine, el cómic $\mathrm{y}$, actualmente, los videojuegos. Una idea vectorial ha de destacarse: el héroe no es, sino que se hace y no es una figura estable sino en perpetuo movimiento que obedece a un canon idéntico, que atraviesa o supera diversas etapas, que tiene un punto de inicio, una eclosión y, si es posible, un retorno. En gran medida puede habitar la región de los prodigios sobrenaturales, pero en lo referente a la Segunda Guerra Mundial, estamos hablando de aquellos que como los se analizarán después se enfrentan a fuerzas fabulosas y ganan de alguna manera una victoria decisiva destruyendo buena parte de la maldad que ha hecho peligrar el mundo que se pretende restablecer (Bou 2000: 108). En la patrulla se trata de proteger a los soldados que acompañan al superior en la misión, pero también de conseguir que el soldado-púber alcance rápidamente la madurez necesaria para, tras las primeras experiencias traumáticas, conseguir, llegado el caso, estar a la altura del resto o incluso, tomar el papel del instructor.

Los héroes poseen características sociales reconocidas como el altruismo, la buena fe, ser portadores de una moral universal, el respeto a las normas sociales además de una serie de habilidades y cualidades no siempre relacionadas con el uso de las armas: valor, sacrificio, diferentes fortalezas, equilibrio psicológico (Esteban Blein 2015: 158) y aunque no siempre manifiesten esa capacidad de empatía y hasta de solidaridad, puesto que se debaten por sobrellevar la cargas que le han sido impuestas y dudan sobre su destino y el de sus compañeros.

Entre los títulos destacados que, para el caso de la Segunda Guerra Mundial, parten de esa patrulla, comando o unidad especial para acometer una acción bélica específica: Sahara (Korda, 1943) Batán (Garnett, 1943), Un paseo bajo el sol (Milestone, 1945), Los desnudos y los muertos (Walsh, 1958), El puente (Wicki, 1959), La cruz de hierro (Peckinpah, 1976), Uno rojo, división de choque (Fuller, 1980), Stalingrado (Vilsmaier, 1992), La delgada línea roja (Malick, 1998), Salvar al soldado Ryan (Spielberg, 1998), Windtalkers (2001). El tono más ácido y problemático de esas unidades se ve incrementado tras el impacto de las guerras del Vietnam o las invasiones de Afganistán o Irak que, en diferentes etapas tienden a subrayar que en esos grupos no se forjan héroes sino más bien asesinos o mercenarios.

Esas películas estudiadas ofrecen un tratamiento muy peculiar de los personajes a los que se les sigue con atención. Antes de la acción, se nos facilita información del origen geográfico, social, cultural y hasta étnico de cada uno de los componentes de esa, a falta de la familia, unidad de integración social. Esas unidades, pese a las diferencias en las estructuras y organizaciones de los diferentes ejércitos, cons- 
tan de cinco hasta la veintena de integrantes dependiendo de las armas específicas. Evidentemente las misiones y las prestaciones y necesidades técnicas pueden llevar a una tripulación mucho más ajustada. En el caso del tanque que protagoniza Fury, uno de los filmes que ejemplificarán gran parte de nuestras aseveraciones, se trata de cinco personas. En el caso de Malditos Bastardos, la misma adaptabilidad del grupo lleva a la inclusión de nuevos elementos por las vías más insólitas. El equipo de expertos de Monument's Man que muestra una especialización enorme debe obrar en diferentes escenarios por lo que se divide o fusiona de manera flexible y variable.

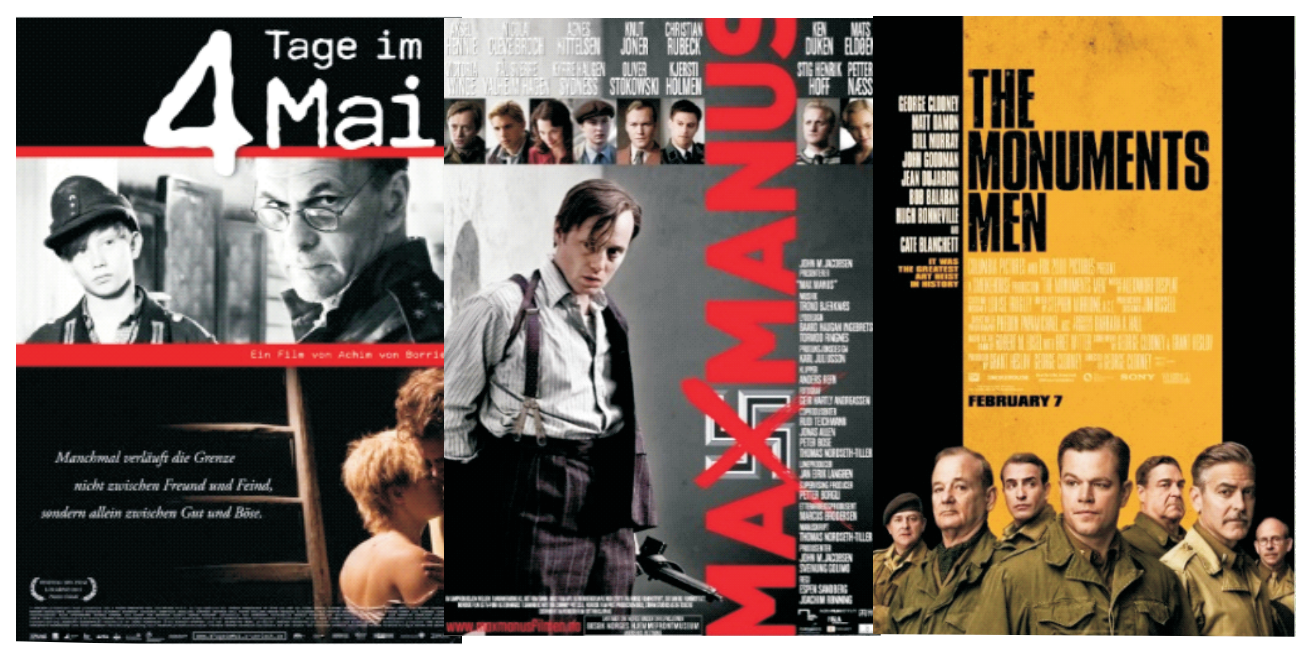

Carteles de 4 días de mayo (izq.), Max Manus (centro), y The Monuments Men (dcha.)

Corazones de hierro (Fury) película norteamericana de David Ayers producida en el año 2012 es una buena muestra de algunas tendencias que se aprecian en ese cine de combate que pone el foco en una pequeña unidad. En este caso, las cuestiones técnicas que acompañan a la tripulación de un tanque son claves: un oficial, el conductor, el encargado de disparar el cañón y los dos ametralladores, cada uno colocado en una determinada área del ya limitado espacio, aunque la movilidad del vehículo pueda compensar ese encasillamiento y las escotillas y visores permitan cierta visibilidad que, en el caso de los submarinos, por ejemplo, están vedadas salvo para el oficial al mando que puede hacer uso del periscopio. En un relato que no se prolonga más allá de unas pocas jornadas, en el contexto del progresivo afianzamiento de las tropas aliadas que se introducen en territorio alemán (¿el infierno?) donde un ejército en repliegue y retirada constante está decidido a librar una dura resistencia y un tanque Sherman, resto de una unidad norteamericana, realiza cuatro misiones. La primera, casi un preámbulo comporta una víctima y el reclutamiento precipitado de un joven soldado y las otras tres corresponden a, en primer lugar, una operación de cobertura de unidades terrestres en un territorio idóneo para emboscadas, una segunda de apoyo a diferentes tropas que toman una pequeña población ya en territorio alemán siguiendo la habitual secuencia de la ocupación casa por casa y, 
por último, una compleja misión que ha de proteger a las avanzadillas aliadas que van a soportar una dura contraofensiva de unidades de las SS y del que solo saldrá indemne Fury que identifica al cañón y a la propia unidad y que, tras una batería decidirá, en un cruce de caminos resistir el avance de un batallón alemán sin tanques pero con vehículos y armamento antitanques. Esa última misión cumplida, aunque comporte el sacrificio de cuatro de los cinco soldados detendrá el avance de la columna enemiga antes de la llegada de los esperados refuerzos.
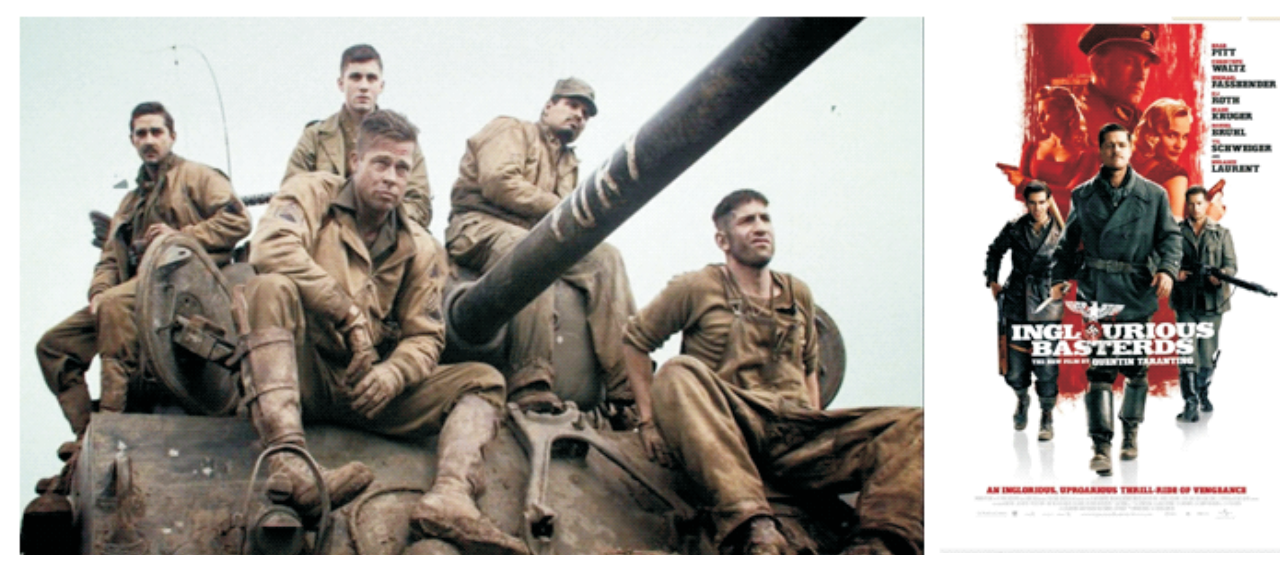

Izquierda: Imagen publicitaria de Corazones de hierro con la tripulación (de izquierda a derecha): el artillero «Bible», los ametralladores Norman y «Gordo» en la fila superior y el sargento «Wardaddy» y «Coon-Ass, conductor y mecánico. Derecha: cartel publicitario de Malditos Bastardos

Independientemente de la calidad cinematográfica de la cinta y de la innumerable colección de planos, secuencias y subtramas más o menos típicas: la ocupación del pueblo alemán con las inequívocas muestras de las acciones represoras de las SS que cuelgan a desertores o a personas que propagasen la desmoralización a la entrada; la bisoñez del oficial que, a diferencia de la veterana unidad de tanques que lleva a cuestas las campañas del Norte de África o de Italia acaba de salir de la Academia y sucumbirá en su primera acción de guerra y la apresurada relación sexual con algunas mujeres alemanas a cambio de una más que equívoca protección y de la más que deseada comida. Hay que subrayar la concurrencia de algunos elementos discursivos que alejan el planteamiento de Corazones de acero de las claves genéricas que hemos destacado de los films de combate que ponen el acento en esa pequeña unidad de combate: 1) No se encuentran marcas o rasgos que determinen una estratificación social o una pertenencia o identificación a una familia, actividad laboral, comunidad o población, más allá de los apodos o de unas fotografías que a duras penas pueden reconocerse en el interior de la cabina, lo que contradice una de las claves habituales de ese tipo de filmes. Las relaciones entre los diferentes soldados son extremadamente agresivas, especialmente con el supuesto aprendiz de guerrero que sufre repetidamente golpes y asedio lo que llega al paroxismo en el momento en 
que, bajo la coartada del endurecimiento, se le hace ser cómplice del asesinato a sangre fría de un prisionero alemán; 2) Cuando la unidad de tanques se ve reducida a única pieza, la jerarquía no ejerce ningún papel destacado y solo la ferocidad del sargento y su supuesta misión de hacerlos regresar a casa con vida permite mantener el grupo cohesionado y operativo. 3) La fidelidad al superior, con algunos rasgos más propios de un grupo de mercenarios alimentados con la promesa de un botín o paga es el único resorte que actúa cuando Wardaddy decide quedarse para defender el enclave en una misión suicida lo que les permite permanecer en ese hogar ambulante en el que se ha convertido el tanque que, aunque inmovilizado, sigue siendo una auténtica fortaleza repleta de armas y de nada fácil destrucción. Nada que ver con aquellos valores de camaradería nacidos desde el civilismo y que anteceden a las fuerzas de combate. 4) Una idea-motriz parece destacarse por encima de las otras: solo se puede combatir con extrema violencia la barbarie del nazismo y, por tanto, los reglamentos, códigos y tratados están bien para los despachos, pero no para las unidades que combaten en territorio enemigo. Son tantos los crímenes perpetrados que, aunque se cumpla una misión que salve a las tropas, el destino de esos soldados no puede ser otro que la muerte. 5) La salvación de joven Norman sirve como expiación a los delitos cometidos en los que solo «Bible» parece no haber participado o, en su fuero interno, se consume porque el perdón no puede enjuagar su propia culpa justificándose todas esas pruebas iniciáticas que, como en la Ilíada, permiten la salvación de aquel que deberá iniciar una nueva vida en otra parte pese a llevar la marca de una experiencia vital eminentemente trágica por que viene precedida de la soledad.

Malditos bastardos (2012) un film de éxito cuyo contenido no puede separarse de la trayectoria y características del director Quentin Tarantino, muestra su profundo conocimiento de los códigos génericos (deconstruidos y fusionados, incluyendo efectos de contrapunto entre música própia del spaghetti-western en los duelos o en el diseño de los títulos de crédito) y hasta subvertidos no oculta una de sus constantes temáticas: la venganza que, de nuevo, al enmarcarse en la $S h o a h^{5}$, adquiere aires de justicia implacable y contemplación sádica que permita, si no reparar, al menos reequilibrar el exterminio de manera ritual. Sin negar las reminiscencias de Doce del patíbulo (The Dirty Dozen, 1969) de Robert Aldrich, la unidad multiétnica comandada por el teniente Aldo Raine tiene su propio código de acción y se mueve en las cada vez más frágiles líneas alemanas en su ordenado repliegue del suelo francés. En la tesis doctoral recientemente aparecida de Jorge Esteban Blein se incorpora al jefe de ese grupo como antihéroe:

A pesar de estar respaldado por sus superiores, Aldo Raine posee su propia moral a la hora de matar, teniendo como modus operandi arrancar las cabelleras de los nazis muertos y dejar a uno con vida para que propague el terror al narrar los acontecimientos de los que ha sido testigo, pero no sin antes haberle marcado una esvástica

\footnotetext{
${ }_{5}^{5}$ Para un exhaustivo repaso a las filmografías nacionales que han tocado el tema de la Shoah véase Insdorf (2003).
} 
en la frente con un cuchillo de caza. Por ello podemos catalogar a ese antihéroe como «justiciero oscuro». (Blein 2015: 146)

El film de Tarantino, pese a todo, aún permite distinguir la bondad de las víctimas como la joven superviviente de una familia campesina francesa que escondía a otro grupo de franceses (judíos) y que, ya en París y a cargo de una pequeña sala de cine, planeará, junto al «comando salvaje» el exterminio de los nazis concentrados en la sala con el propio Adolf Hitler a la cabeza. ¿Acaso no sería ese el sueño del cinéfilo vengador que, como en el filme, utilizando la rápida combustión del nitrato de la película, acabaría con esa concentración de gerifaltes nazis? La película no se olvida de las productoras francesas que siguieron creando películas denostadas por los críticos por colaboracionistas pero reivindicadas por autores e historiadores como Bertrand Tavernier ni tampoco de algunos personajes como el resistente alemán que como aquellos jóvenes idealistas del grupo La Rosa Blanca y los hermanos Schöll entre otros pusieron en jaque a la Gestapo antes de ser detenidos, juzgados y ejecutados y nos sirve como muestra para, aceptando la máxima exposición a una violencia paródica, hablar de otros temas como el de la producción cinematográfica durante la Segunda Guerra Mundial o el propio genocidio y la resistencia en territorio ocupado.

Muy brevemente mencionaré la importancia de otros cuatro títulos que, de una manera algo más optimista, vuelven a conectar con algunas tradiciones que los dos títulos anteriores pulverizan en buena medida: la cinta noruega Max Manus (2008) de Joachim Rønning y Espen Sandberg que reconstruye la trayectoria vital de una de las unidades de la resistencia noruega más activa tras su instrucción en territorio británico; 4 dias de Mayo (4 Tage im Mai, 2011) de Akim von Borries, coproducción ruso-alemana-ucraniana que plantea la rebelión de una pequeña unidad soviética que decide enfrentarse a su propio ejército al querer proteger a las niñas de un orfanato en una isla de la costa báltica, hecho que, tal vez, ahondaría en la tesis de que el ejército de Stalin podía ser aún más perverso que el mismísimo ejército alemán; la estadounidense Company of Heroes (2013) de Don Michel Paul que, inspirada en un videojuego, aglutina diversos soldados de diferentes nacionalidades (británico, polaco, canadiense...) que se unen para realizar una peligrosa misión de destrucción de una auténtica «arma de destrucción masiva» $\mathrm{y}$, finalmente, la también estadounidense The Monuments Men (2014) de George Clooney, pequeño grupo especial de veteranos oficiales de diferentes ejércitos que se unen para localizar y salvar diferentes obras de arte en poder de los nazis y que, de manera coordinada, han de evitar el traslado de esos tesoros a Alemania. El tema, que no es nuevo, sí aporta una interesante y optimista misión porque, se sobreentiende que, esas obras deben ser compartidas por toda la Humanidad y, de alguna manera, contienen la semilla de todo lo bueno que podemos encontrar en todos los hombres.

Como conclusión solo cabe destacar que cada nuevo conflicto bélico deja su impronta en las producciones cinematográficas actuales que, difícilmente pueden ser realizadas sin el apoyo de los diferentes Ministerios y Departamentos de la Defensa, hecho que es suficientemente significativo. Sin abogar por el retorno a ese cine clásico de los civiles que han de defender a su patria sin cuestionar nada más y 
suspirando por sus familias, sus novias o sus granjas, sí hemos de ser capaces de detectar qué mensajes propagandísticos (lo discursivo) se encierra en las imágenes cada vez más impactantes de ese cine bélico que, al igual que las guerras, sigue modelando nuestra percepción y, tal vez, nuestro futuro.

\section{Referencias bibliográficas}

Altman, Rick (2000): «Los géneros cinematográficos». Barcelona, Paidós.

BAsINGER, Jeanine, (1986): The World War II Combat Film. Anatomy of a Genre, Columbia University Press, Nueva York.

BEEvor, Antony (2002): «Berlín. La caída: 1945». Barcelona: Crítica.

BoU, Núria, PÉREZ, Xavier (2000): «El temps de l'heroi. Ėpica i masculinitat en el cinema de Hollywood». Barcelona: SITGES Festival Internacional de Cinema de Catalunya, Paidós.

Butler, Ivan (1974): «The War Film». London: The Tantiry Press

ESTEBAN BLEIN, Jorge (2015): «El antihéroe como protagonista en el guión épico americano contemporáneo: estrategias identificatorias y evolución heroica». Madrid, Universidad CEU San Pablo (director Dr. D. Juan Orellana Gutiérrez de Terán)

INSDORG, Annette (1983): «Indelible Shadows. Film and the Holocaust». Cambridge, Nueva York: Cambridge University Press.

JEAvOns, Clyde (1974): «A Picturial History of War Films». London: The Hamlyn Publishing Group Limited.

Morella, Joe, EpsteIn, Edward Z., GriggS, John (1975): «The Films of World War II. A Pictorial Treasury of Hollywood's War Years». Secausus. New Jersey: The Citadel Press.

PAUWELS, Jacques R. (2002): «El mito de la guerra buena. EE.UU. en la Segunda Guerra Mundial». Hondarribía: Hiru.

SÁNCHEZ BARBA, Francesc (2005): «La II Guerra Mundial y el cine». Barcelona. Ediciones Internacionales Universitarias.

Sorlin, Pierre (1993): «Guerra, Medios Audiovisuales y Sociedad». En Actes del Congrés Internacional Guerra, Cinema i Societat. Una aproximació metodologica Barcelona 1215 de febrero de 1992. J.M. Caparrós Lera, J.M., S. Alegre y Lluís Anyó (eds.), vol. III, pp. 7-18. Universitat de Barcelona.

Whiteclay Chambers II, John, Culbert, David (1996): «World War II». New York and Oxford: Oxford University Press. 